\title{
La filosofía del derecho krausista: luces y sombras ${ }^{1}$
}

\section{Delia Manzanero ${ }^{2}$}

Recibido: 19 de junio de 2015 / Aceptado: 22 de febrero de 2016

Resumen. Este artículo analiza algunos de los aspectos de la teoría jurídica y sociológica krausista más cuestionables, aquéllos que han sido total o parcialmente impugnados y refutados por la crítica contemporánea, así como aquéllos que han sido aprobados e incorporados como exigencias irrenunciables en nuestro sistema jurídico actual. Para ello, se exponen los lineamientos generales de la relación entre los binomios estado-sociedad y derecho-educación que la filosofía jurídica krausista plantea, a fin de reflexionar sobre las virtudes e insuficiencias de su doctrina.

Palabras clave: Estado; moralidad; derecho inmanente; krausismo; coacción.

\section{[en] The krausist philosophy of law: lights and shadows}

\begin{abstract}
This article discusses some of the most questionable aspects of the Krausist legal and sociological theory, those which have been wholly or partly challenged and refuted by contemporary criticism, as well as those which have been approved and incorporated as essential demands in our current legal system. To this end, the general guidelines of the relationship between the binomials of state-society and law-education raised by Krausist legal philosophy are discussed, in order to reflect on the strengths and weaknesses of this doctrine.
\end{abstract}

Keywords: State; morality; immanent law; Krausism; coercion.

Sumario: 1. Reducción del Estado Nacional a Estado Educador. Las insuficiencias del intimismo político-social de base educativa krausista; 2 . La falta de seguridad jurídica: una crítica al eticismo antinormativista krausista; 3 . La educación en el derecho: ¿es la educación una panacea o un instrumento social con un eficaz papel preventivo?; 4. Consideraciones finales; 5 . Referencias bibliográficas.

Cómo citar. Manzanero, D. (2017): "La filosofía del derecho krausista: luces y sombras", en Revista Anales del Seminario de Historia de la Filosofía 34 (1), 147-161.

1 Esta investigación se ha realizado en el marco del proyecto de investigación de la Universidad Pontificia Comillas: "Krause y el krausismo del sexenio democrático" (Proyecto de investigación I+D+i: HAR201679448-P, 2016-2019), financiado por el Ministerio de Economía y Competitividad. Asimismo, este estudio se inscribe dentro de una Ayuda Juan de la Cierva - Formación Posdoctoral adscrita a la Universidad Rey Juan Carlos de Madrid, financiada por el Ministerio de Economía y Competitividad (FPDI-2013-17242).

2 Universidad Rey Juan Carlos deliadelos@hotmail.com 


\section{Reducción del Estado Nacional a Estado Educador. Las insuficiencias del intimismo político-social de base educativa krausista}

Francisco Giner de los Ríos y Adolfo Posada, como otros muchos institucionistas españoles, se habían formado en la filosofía krausista, cuyo proyecto pedía fundamentalmente la modernización de España. Esta vía hacia el reformismo que proponen Giner y los krausistas españoles debía llevarse a cabo a través de la educación y de la acción cultural y ética, principalmente. Se trataba pues de una vía evolutiva, de un reformismo gradual y pacífico, lo cual implicaba un rechazo de las medidas violentas revolucionarias para llevar a cabo ese progreso social y político. En su obra, vemos cómo Francisco Giner se opone constantemente a las revoluciones de carácter violento, de uno u otro signo, y afirma -comulgando en ello con corrientes antimaquiavélicas- que "el fin no santifica nunca al medio"3. La función que cumple la educación en su obra es claramente positiva, pues ofrece un sentido regulativo, en tanto ideal que apunta a orientar nuestros actos en la medida de lo posible, y ante el cual debemos persuadirnos de que alguna vez llegará a existir. Esta misma vocación es suscrita por otros krausistas contemporáneos de Giner, quienes comparten con nuestro autor una concepción platónica que apuesta por la necesidad y el valor del deber ser del ideal en tanto guía directiva de la humanidad, mostrando así que "para enseñar al mundo cómo debe ser, no siempre [se] llega tarde" . Concebida la educación y la elevación del nivel cultural de los ciudadanos como principal vía de transformación y promoción de los españoles, era natural que los krausistas atribuyeran al Estado la función prioritaria de la enseñanza, del aumento de la información y la elevación del nivel cultural del pueblo a través de la acción educativa, que fue inicialmente propuesta en los núcleos Universitarios y que luego fue dirigida fundamentalmente hacia la escuela ${ }^{5}$.

En efecto, una de las misiones educativas que acometió el krausismo fue esta labor fundamental de enseñar a los ciudadanos el valor de su poder moral dentro del Estado, pues de la formación de hombres honrados, de la pedagogía, dependía en última instancia la formación de un Estado sólido. En consecuencia, su pensamiento político se desarrolla mirando hacia adentro, haciendo radicar en la conciencia del hombre el apoyo más firme de la constitución política.

La teoría organicista de la sociedad formulada por Krause parte pues de cierta impronta platónica, como puede apreciarse en su doctrina del microcosmos del Estado individual, también denominado por Platón como república interior del hombre, donde el individuo constituye un Estado, soberano, autónomo e inviolable en su vida y derecho interior. A fin de dotar de autonomía y soberanía a cada ciudadano, Giner dirige sus críticas a la tesis del formalismo jurídico, para el cual la coacción es

Giner de los Ríos, F. y Calderón Arana, A.: Resumen de Filosofia del Derecho, por Francisco Giner, profesor en la Universidad de Madrid y en la "Institución libre de Enseñanza", y Alfredo Calderón, doctor en Derecho. Madrid, OO.CC., Tomo II, t. XIV, 1926, p. 148.

4 Giner de los Ríos, F.: "Sobre el concepto de la ley en el Derecho positivo". BILE [Boletín de la Institución Libre de Enseñanza]. LV, tomo I, 1931, pp. 218-226.

5 Vázquez-Romero, J. M.: "Sociedad, Derecho y Ciencia en los escritos de Giner de los Ríos". En: Álvarez Lázaro, P. F., Vázquez-Romero, J. M. (Eds.): Krause, Giner y la Institución Libre de Enseñanza. Madrid, Editorial Parteluz, Universidad Pontificia Comillas, 2005, pp. 107-129. Vázquez-Romero, J. M., "La sociedad científica en los escritos ginerianos del sexenio". En: El Basilisco, (n 38, enero-diciembre, 2006), pp. 77-94.

6 Platón: La República. Introducción de Manuel Fernández-Galiano, Traducción de José Manuel Pabón y Manuel Fernández-Galiano, Madrid, Alianza Editorial, Clásicos de Grecia y Roma, 2006, p. 199 (568b). 
una nota esencial del Derecho. Ello es refutado por Giner al mostrar la existencia de una esfera jurídica autónoma en toda persona individual donde es manifiestamente imposible la coacción: en el individuo encontramos pues un derecho provisto de las notas de intersubjetividad y estatalidad -Giner retoma aquí el concepto platónico de Estado individual- pero en el que no cabe hablar de coactividad, sino a lo sumo de auto-convicción lograda por la suma de las decisiones personales. En las tesis de Clarín, donde encontramos una clara huella de la doctrina krausista, viene recogido este pensamiento con una formulación literaria muy expresiva:

existe una esfera del derecho en que nada trasciende al exterior (directamente) que es la esfera del derecho inmanente, en que cada cual es juez de sí mismo, con su conciencia; así existe la frase vulgar hazle justicia, así los personajes más vulgares de Shakespeare dicen con frecuencia "bribón, manda que te ahorquen", y así existe un sagrado respeto a las intenciones en que es naturalmente imposible la coacción, y aún imposible el conocimiento de las determinaciones para todos menos para la propia conciencia ${ }^{7}$.

La educación y la ética de ese hombre interior, al que Giner dota de entidad jurídica al darle el estatuto de Estado individual, explican así este característico intimismo político-social de base educativa que está presente en las principales obras de filosofía del derecho krausistas ${ }^{8}$. A estas raíces claramente platónicas se remite su discípulo, Adolfo Posada, quien refiere las siguientes notas a los Principios del Derecho Natural ginerianos: "en ella una resultante original, en la que se funden con cierto idealismo de sabor platónico, el rigorismo del imperativo kantiano, el realismo de la escuela histórica, el eclecticismo krausista omnicomprensivo... Todo, recogido en una concepción sintética propia, que habrá de acentuarse y tomar nuevos matices y mayor intensidad en labores ulteriores".

La utilización del concepto del "Estado individual" como elemento último e irreductible que entiende al individuo como Estado-célula dentro del organismo social, es muy recurrente en toda la literatura krausista y tiene un especial desarrollo en la filosofía del derecho de Giner. Esta teoría del Estado individual supone reconocer la existencia de un Derecho inmanente que posee unas interesantes aplicaciones en la comprensión del punto de vista subjetivo del Derecho y que viene a asentar las bases de la obligatoriedad de las normas jurídicas y su grado de aceptación en sociedad. En los testimonios de la época, encontramos una referencia expresa a esta adaptación del concepto de derecho inmanente de raíz platónica en la filosofía de Krause, pues como hiciera notar Fernando de los Ríos: "A partir del pensador griego, comienza la historia de la consideración del derecho como una propiedad del sujeto; del derecho como inmanente; esto es de importancia capital en su concepción de la justicia (en Platón sinónimo de derecho), que renace en Leibniz, y vuelve a aparecer en Krause" $"$.

7 (Clarín) García-Alas y Ureña, L.: "El derecho y la moralidad". Revista Europea. t. XII, n. ${ }^{\circ}$ 240, 29 septiembre 1878, p. 364.

8 Cfr. Giner de los Ríos, F. y Calderón Arana, A.: Resumen de Filosofía del Derecho. Tomo II, op. cit., p. 153 y pp. 160-ss.

9 Posada, A.: "Prólogo". En: Giner de los Ríos, F.; Calderón, A., Prolegómenos del derecho. Principios de derecho natural, sumariamente expuestos por Francisco Giner, profesor de Filosofía del Derecho en la Universidad de Madrid, y Alfredo Calderón, alumno de la misma. Madrid, OO.CC., t. I, 1916, p. XIV.

10 Ríos Urruti, F. de los: "La filosofía política en Platón". Obras Completas. Madrid, Anthropos Editorial, 
Los krausistas proponen así un concepto de Derecho Inmanente que abarcaría el carácter interior de la vida jurídica, de manera que no niegan la posibilidad, pero sí la necesidad de que exista coacción para que podamos hablar de Derecho. Basándose en esta idea, la filosofía jurídica krausista establece la distinción, por un lado, entre un poder necesario, conditio sine qua non para realizar todo Derecho, el cual radicaría en el ser plenamente jurídico, es decir, en la persona; y, por otro lado, un poder coactivo, el Derecho del Estado nacional, cuya necesidad y posibilidad no se niegan, pero sí su prevalencia, pues esta coacción no es sino una nota material y externa que no tendría lugar en el Derecho inmanente, ni en el social regido por la costumbre, esto es, la opinión pública, por lo que tan sólo se podría aplicar bajo estrictas condiciones al Derecho legislable ${ }^{11}$.

De ahí el papel decisivo que los krausistas otorgan a la opinión pública y a la educación, los cuales son -en palabras de Posada- determinantes para garantizar la legitimidad democrática, pues "el Estado, en su relación final, entraña la expresión jurídica circunstancial de la cultura misma, o sea el ideal de vida; y su acción se distingue por el modo como actúa"12. Por consiguiente la clave del sistema krausista supone un esfuerzo, no tanto por imponer la soberanía, como por reivindicar el valor de la autonomía, término preferido por los krausistas:

Desde este punto de vista, la soberanía del estado no se expresa tanto en el poder de dominación sobre el exterior - poder agresivo, de absorción- como en el de dominación sobre sí: autonomía; la noción de la supremacía debe sustituirse quizá por la de autonomía; tan cierto es esto, que el proceso de la formación de los estados, acaso se puede interpretar como un proceso de formación -educación- de una fuerza interna de dirección racional, libre, según el ideal que a la vez se va elaborando y realizando ${ }^{13}$.

Hoy en día diríamos, reformulando dicho desiderátum krausista en términos más modernos, que se trata de la formación de ciudadanos capaces de actuar en la esfera pública, transformando las oportunidades de participación en ocasiones reales de autodeterminación:

puede decirse que el problema fundamental de la representación democrática no está tanto en el socavamiento de la soberanía y en la migración del poder fáctico hacia instancias de poder supra- o trans- nacionales débilmente representativas. Lo verdaderamente relevante es más bien la desintegración de todo espacio homogéneo de ordenación de los deseos, los intereses y las necesidades, la desaparición de una base común sobre la cual establecer equivalencias significativas entre las demandas de todos. Es la posibilidad misma de la representación la que se evapora junto con la creencia, típicamente moderna, de que es posible modelar el mundo por medio de la potencia del soberano, el artífice del orden social. En último término, es la proyectabilidad misma de los equilibrios y las normas básicas de la convivencia lo que está en cuestión ${ }^{14}$.

Fundación Fernando de los Ríos, 1997, p. 23.

11 Giner de los Ríos, F. y Calderón Arana, A.: Prolegómenos del derecho. Principios de derecho natural. op. cit., p. 26.

12 Posada, A.: "El fin del Estado". BILE. XXXIX, tomo I, 1915, pp. 141-142.

13 Posada, A.: "La soberanía”. BILE. XXXIX, tomo II, 1915, pp. 249-250.

14 Greppi, A.: La democracia y su contrario. Representación, Separación de Poderes y Opinión Pública. Madrid, Trotta, 2012, p. 46. 
De acuerdo con esta concepción de la autonomía, Giner demanda una mayor atención a la educación de individuos y pueblos en un espíritu de justicia, oponiéndose así a todo modelo de legislación definida en términos puramente coactivos, cuyos intentos de imposición no respondían a lo que Giner pedía para su contexto histórico. En coherencia con este principio de renuncia de toda coacción exterior, se pronuncia Giner en contra del servicio militar, al que connota como servicio de servidumbre y de sumisión a la imposición de la fuerza: "el de la servidumbre (que no servicio) militar, en que a lo sumo, no ven otro mal que la redención a metálico, y otra reforma que extendernos a todos el yugo" -y añade Giner su principio ético- "bueno fuera, si entrase en ella la obra de redimirse por dentro"15.

La coacción y el uso de la fuerza en el Derecho quedaría reconocida, pues, como una posibilidad de disposición de medios necesaria, como un poder que necesita fuerza para realizarse, pero que no es esencial al concepto de Derecho porque éste último, en términos krausistas, también comprende la soberanía que se da en cada individuo. Así lo expresa Giner al afirmar que el Estado "las más de las veces es impotente para evitar la injusticia (sobre todo de un modo directo), y siempre inferior su eficacia a la del sano sentido del individuo y la sociedad, o sea el espíritu de justicia, a la rectitud de conciencia, que es de donde únicamente cabe esperar el completo remedio" $"$.

La importancia aquí del individuo, como último órgano y emblema político, constituye uno de los grandes pilares del pensamiento jurídico krausista: la tesis de que el reconocimiento de la regla del Derecho por la voluntad del sujeto jurídico es un elemento imprescindible para su cumplimiento, viene explicada por Fernando de los Ríos con el siguiente razonamiento: "No es tan sólo el hombre un depósito social: tiene el centro en sí mismo y hay una función que es específicamente suya. Sólo él da objetividad al pasado, y por su carácter ético, es decir progresivo, hace avanzar en su valor moral" ${ }^{17}$. Así también lo expresa el discípulo y coautor de muchas obras con Giner, Alfredo Calderón, cuando afirma que:

Todo el orden del Derecho se refiere para su cumplimiento a la libre voluntad de la persona [...] La obligación jurídica nunca nace, por tanto, propiamente de la voluntad, sino del orden objetivo del derecho. Pero este orden, para ser efectuado, necesita ser reconocido previamente por el sujeto que resuelve en su vista atemperar sus actos a las prescripciones del mismo. En esto consisten las que pueden denominarse de una manera general declaraciones de voluntad, de las cuales es un caso particular el reconocimiento de la regla de Derecho ${ }^{18}$.

Al hacer del individuo un sujeto de derecho, la teoría krausista del Derecho Inmanente trata de enseñar al hombre a ser consciente de los fines éticos que debe cumplir y realizar libremente. Esta idea del Estado individual se encuentra, por supuesto, en perfecta coherencia con el pensamiento krausista de que la educación, la instrucción y la civilización del pueblo son los verdaderos garantes de una reforma sólida y estable. Algunos de sus proyectos han tratado de contribuir, en definitiva,

\footnotetext{
Giner de los Ríos, F.: "Notas de Sociología”. BILE. XXII, tomo II, 1898, p. 350.

Giner de los Ríos, F. y Calderón Arana, A.: Resumen de Filosofía del Derecho. Tomo II, op. cit., p. 122.

Ríos Urruti, F. de los: "La obra de la cultura: Ética y Educación”. BILE. XXXII, tomo II, 1908, p. 305.

Calderón Arana, A.: "El contrato y el Derecho”. BILE. X, tomo II, 1886, pp. 252-253.
} 
al progresivo reconocimiento de la subjetividad internacional del individuo y han tenido una influencia determinante en la fundamentación del sistema de los derechos humanos. Dada esta manifiesta presencia de los conceptos filosóficos y políticos krausistas en la revalorización del papel del sujeto humano en el proceso de identificación y de justificación racional de los valores ético-jurídicos según su ideal de autonomía, consideramos interesante el estudio de estos autores no sólo por la difusión y el importante papel que tuvieron para su contexto, sino también para comprender su función histórica y su papel en el contexto en que se forjaron los derechos humanos ${ }^{19}$.

Sin embargo, esta absoluta sobrevaloración de la ética y de la educación trae consigo algunas consecuencias prácticas peligrosas para la seguridad jurídica del individuo, como el hecho de que este énfasis en el aspecto ético venga a reducir, en cierto modo, la función del Estado a la de Estado educador. De tales implicaciones político-sociales nos ocuparemos en la siguiente sección.

\section{La falta de seguridad jurídica: una crítica al eticismo antinormativista krausista}

Si bien reconocíamos algunas cualidades interesantes y valiosas en la crítica frontal que la teoría jurídica krausista hacía a las concepciones del Derecho que lo limitan a un sistema de coacción organizada, esta oposición krausista a la institucionalización del Estado y de su fuerza coactiva ha de ser tomada con mucha cautela y debe ser matizada.

Conviene pues reparar en la insuficiencia de algunas de las soluciones krausistas e incluso, en algunos de los peligros que llevaría consigo esta ingenuidad del eticismo krausista. En su permanente intento de rectificación del formalismo mecánico y técnico del liberalismo abstracto y sus críticas a la Restauración canovista, los krausistas parecen olvidar el problema de la realización práctica de la seguridad jurídico-política, al subordinarla constantemente a valores de indudable rango ético, pero que son, sin embargo, muy discutibles, más difíciles de imponer y, sobre todo, enormemente susceptibles de ser manipulados y traicionados ante la carencia de un sistema coactivo y formal que los rija.

Por lo demás, al afirmar los krausistas que el Estado tiene conciencia-o mejor, que no hay más Estado que la conciencia de los sujetos individuales que lo integran-y que esas conciencias particulares le impulsarán a cumplir el derecho, parecen afirmar con ello que el problema del Estado de Derecho se pueda resolver psicológica y éticamente, sin necesidad de la participación de los mecanismos de control propios del Estado liberal de Derecho. Es, por lo tanto, importante constatar que, bajo el pretexto de acercar el Derecho a la vida, con frecuencia esta doctrina parece adherirse a posturas que apuestan por una completa des-formalización de lo jurídico y por un explícito y peligroso antinormativismo. Recordemos cómo Giner dirigía sus críticas, tan características por otra parte de la doctrina krausista, al legalismo formalista, en línea con la tradición iusnaturalista clásica idealista de Platón y Fray Luis de León:

19 Véase un trabajo sobre la defensa krauseana de los derechos humanos: Querol Fernández, F.: La filosofia del derecho de K.Ch.F. Krause. Con un apéndice sobre su proyecto europeista. Universidad Comillas, Unión Editorial, Madrid, 2000. 
El célebre pasaje de la República de Platón, en que viene a declarar que la ley es innecesaria para el hombre educado; y se burla de querer suplir la falta de educación y de sentido interno, que es su fruto, formando reglamentos sobre reglamentos, añadiendo correcciones sobre correcciones, con que no se logra sino complicar y empeorar la enfermedad, "cortando las cabezas de la hidra". También en las Leyes, reputa vergonzoso suponer que haya hombres tan malvados, que el legislador tenga que dictar leyes para contenerlos. Naturalmente, todas estas afirmaciones son luego atenuadas, pero queda siempre como signos de un cierto ideal. Ahora, nuestro Fray Luis de León; como platónico que es, comenta el pasaje de la República y abunda en su sentido, en sus Nombres de Cristo [Libro I, \& IV; libro II, \&\& II y III, etc.], considerando que la ley es cosa imperfecta, por ser monótona y "terca", no viva; por oposición a la gracia, viva y atractiva (no meramente intelectual como aquélla), individual, en suma, para cada caso y sujeto, flexible. [...] Repárese que éstas son precisamente las faltas que suelen poner muchos anarquistas a la legislación: v. gr., uno de los libertarios más famosos norteamericanos, Fulton [ La Edad del Pensamiento (The age of thought) $]^{20}$.

Como puede apreciarse, en el Estado de Derecho krausista, la ética y la educación constituyen los supremos resortes para hacer cumplir y para dotar al sistema jurídico, no sólo de legitimidad, sino también de legalidad, y aquí es donde quizá radica el talón de Aquiles de esta doctrina: en la falta de un eficaz mecanismo de garantía y de control.

... la labor de la historia parece ir condicionando la sociedad a un estado de concienciación en que se haga dueña de sí, y domine su naturaleza como va haciéndolo con el mundo exterior; todo elemento de fuerza será, pues, eliminado por inútil. Este optimismo con pequeñas diferencias, parece ser muy general. Tal vez el Sr. Giner de los Ríos, pueda decirse que participa de él. [...] Esta importancia extrema que para el gran pensador griego [Platón] tuvo la educación, es un motivo más de acercamiento a nuestros días. La nota exterior coercitiva parece ser estimada cada vez menos en cuanto no sea un medio para llegar al interior y producir una reforma en la modalidad ética. [...] la educación, solo de la eficacia de su labor depende el que la humanidad salga de la trágica situación presente. Ella es la integral de todas las diferenciales constitutivas del orden sociológico ${ }^{21}$.

Enunciaciones de este tipo son las que han llevado a varios autores contemporáneos a criticar la filosofía krausista por su ingenuidad y por la falta de control en su propia teoría del Estado.

Dos serían los peligros fundamentales que acechan a dicha concepción eticista del derecho:

a) Por un lado, la disolución de la objetividad del Derecho en un, cada vez mayor, acentuado voluntarismo subjetivista al que se apunta en la doctrina de Giner. Así lo expresaba Fernando de los Ríos, describiendo esta raíz platónica en la filosofía jurídica gineriana que hace residir las garantías del derecho únicamente en la educación, sin percatarse quizá del peligro de subjetivismo relativista del que adolecería dicha doctrina si se tratara de aplicar en tiempos de un difundido pluralismo ideológico y social como el actual.

Giner de los Ríos, F.: “Aspectos del anarquismo”. BILE. XXIII, tomo I, 1899, p. 88.

Ríos Urruti, F. de los: "La filosofía política en Platón”. op. cit., pp. 35-36; p. 55. 
b) Por otro lado y, en conexión con lo anterior, debemos señalar la insuficiencia y limitaciones de un Estado meramente educador para mantener una seguridad jurídica mínima para los ciudadanos. En efecto, el iusnaturalismo krausista se preocupa más por la justicia del Derecho que por su legalidad; pero aquí radicaría precisamente el peligro de esta tendencia. Al esperar el completo remedio del espíritu de justicia del pueblo y de la rectitud de la conciencia de sus ciudadanos, $\mathrm{y}$, al mismo tiempo, despreocuparse en demasía de la vinculación necesaria de los ciudadanos y juristas a la ley, se está eliminando así toda seguridad jurídica. Asimismo, cabe hacer notar que la pretendida justicia de las conclusiones que puedan alcanzarse en derecho, si no se atienen a una normatividad legal, puede transformarse fácilmente en arbitrariedad e incluso en una nueva injusticia.

Una de las apreciaciones más repetidas de la doctrina krausista que adolece de este optimismo desproporcionado, es la de que todo depende del alto o bajo nivel de moralidad de una comunidad, de la buena intención de los ciudadanos o de la conciencia de ese gran individuo que es el Estado paternalista. De hecho, la creencia krausista de que, mediante la gran panacea de la educación se pueden solucionar todos los problemas, resultó particularmente funesta e inoperante en su contexto histórico. Algunas obras ya han acentuado las dificultades a las que tuvo que hacer frente esta posición krausista de un acentuado optimismo ético, al hacer notar que los defensores de la I República

eran catedráticos, profesores, periodistas, abogados... hombres de buena voluntad influidos hondamente por la filosofía krausista, defensora de una ética laica y la libertad de conciencia. Su sueño era un Estado descentralizado, una sociedad más justa, una educación popular, la proclamación de la libertad religiosa y la abolición de la esclavitud en las colonias. Les faltó pragmatismo y unidad ante los enemigos comunes para hacerlo realidad y les sobraron problemas: las estrecheces de la Hacienda, el levantamiento carlista en el norte, la guerra de Cuba, la deslealtad del ejército, la combatividad campesina y la agitación urbana decidida a llevar hasta el final el proceso revolucionario ${ }^{22}$.

Tal y como señala Recaséns Siches, esta visión platonizante de la realidad jurídica constituye quizá la parte no sólo más inoperante, sino la más discutible y controvertida de la filosofía jurídica gineriana:

Cierto que la aportación de Giner y de su escuela a la Filosofía del Derecho fue fecunda y que sobrevivieron varios de sus ideas magistrales; pero también es notorio que, sobre todo en la Teoría jurídica estricta, su preocupación moralista de tipo platonizante, contribuyó a obscurecer los perfiles de algunas nociones básicas, como la de Derecho, la de Estado, etc.: así como también decayeron pronto aquellos pensamientos que se inspiraban en una metafísica romántica. Mucho más importante perdurable, en cambio, fue su contribución práctica como actitud y disciplina de ideales jurídicos-políticos ${ }^{23}$.

22 García Cortázar, F.: Historia de España, Editorial Planeta, Barcelona, 2003, pp. 210-211. Citado a partir de: Enériz Olaechea, F. J.: "El proyecto de Constitución Federal de la I República Española (1873)". En: Revista jurídica de Navarra. No 37, 2004, p. 115.

23 Recaséns Siches, L.: Panorama del pensamiento jurídico en el siglo XX. México. Editorial Porrúa, primer tomo, primera edición, 1963, p. 20. 
Por esta razón, convendría aquilatar y tomar con mesura la más que cuestionable crítica que los krausistas hacen de algunos aspectos garantistas del liberalismo, así como su intento de eliminar la coacción por completo como elemento típico del Derecho. Hoy por hoy no parece muy convincente la tesis krausista que pronostica la total desaparición del Derecho y su sustitución por normas no-coactivas de organización o por normas exclusivamente de carácter ético, no al menos en un futuro relativamente cercano. Si fuéramos capaces de imaginar o pensar en una sociedad en la que esas circunstancias ideales krausistas se cumplieran: una sociedad en que las normas jurídicas se obedecieran por su propia bondad y justicia, y no por miedo a la imposición de una sanción en caso de incumplimiento; una sociedad en la que la aceptación social y la participación de la ciudadanía en el Derecho hagan coincidir completamente lo que Giner denomina el Estado oficial con el Estado real; una sociedad, en definitiva, en la que el número de supuestos reales y concretos en los cuales la coacción tenga que ser utilizada se vea significativamente reducida; si fuéramos capaces de pensar o imaginar esta sociedad, es muy probable que, a pesar de todo, la coacción continuara siendo necesaria.

En efecto, la coacción se encuentra siempre detrás de todo orden social y, aunque en la mayoría de ocasiones no actúe, nunca desaparece. Puede muy bien decirse, que a ese cumplimiento espontáneo del Derecho que vemos en la mayoría de los casos, no le es quizá del todo ajeno el hecho de saber, con toda certeza, que la coacción jurídica puede actuar plenamente en cualquier momento en que resulte necesario para la defensa del ordenamiento jurídico. Esta idea es algo que los krausistas sencillamente no contemplaban en su crítica a este modelo del Derecho coactivo.

A pesar de esta matización que hacemos a la doctrina krausista, hay que añadir, por poner algo en el otro lado de la balanza, que no les faltó sutileza para darse cuenta de que la coacción jurídica no era la única -ni quizá la mejor- forma de imponer sanciones o de hacer cumplir el derecho. Al hablar de la educación y de la moralidad, estaban propugnando otro método de ordenamiento social que no estaba exento de imponer su propio tipo de sanciones, ciertamente no coactivas, pero no por ello menos eficientes. Los krausistas eran pues conscientes de que no sólo existen sanciones de tipo coactivo y exterior como las del Derecho, sino que hay otros diversos tipos de sanciones que implican diferentes modos de "cautividad" en el sujeto, por ejemplo, las que sirven para imponer determinado orden social a través de imposiciones morales. Algo que algunos autores contemporáneos quieren significar con la expresión de que, a la hora de mantener el orden un sacerdote cumple mejor dicha función que cien gendarmes.

Esta sujeción moral del sujeto estaría provista de modos de coacción personal efectivos y de sanciones que operan de modo eficaz, y que pueden ser de diversos tipos: a). las trascendentes, como el premio o castigo en una vida ultra-terrena; b). las sanciones internas, como la culpa, frustración, etc.; y c.) las sanciones sociales, como la pérdida del prestigio y del honor o la marginalización del grupo, entre otras. Estas últimas sanciones que se nos imponen por no respetar los usos de una determinada sociedad, puede que, en efecto, no utilicen el recurso de la fuerza y la coacción, pero no por ello puede decirse que las sanciones derivadas de las normas morales sean menos graves o constriñentes que las derivadas de las normas jurídicas. Con cierta frecuencia, lo cierto es precisamente lo contrario: en algunas ocasiones las sanciones morales son las más duras de padecer. Es pues posible que muchas de las sanciones jurídicas puedan considerarse menos duras e infamantes que una 
sanción derivada de la violación de una norma ética, y ello es debido a la falta de una formalización institucional de las sanciones éticas y sociales. La moral conlleva pues unas imposiciones y unas sanciones personales y sociales, que si bien prescinden por completo de toda coacción física, tal y como desean los krausistas, sí que suponen una normatividad y un condicionamiento social que puede en ocasiones alcanzar niveles de muy difícil ineludibilidad.

Este sería el peligro que tiñe todo el pensamiento krausista, al arriesgarlo todo en favor de la ética, de los valores, de un tácito y, a veces explícito, menosprecio de la fuerza como instrumento apto para garantizar un sistema político de corte liberal. En otras palabras, el adolecer de una sanción determinada hecha explícita y acordada por todos, hace que no haya una seguridad mínima y que la ambigüedad en que queda expresada la norma ética pueda ser interpretada de modo que la sanción se amplifique en determinados casos hasta límites insospechados.

Frente a esta vaguedad y ambigüedad de un modelo jurídico que encumbra el reconocimiento moral como último depositario y garantía del derecho, lo que pretenden otros conceptos más legalistas del Derecho es imponer un criterio de certeza a través de un sistema organizado, formalizado e institucionalizado de sanciones que se lleve a cabo por órganos específicamente creados para ello, lo cual es la base precisamente de un valor tan fundamental e irrenunciable como el de la seguridad jurídica.

Por lo tanto, conviene atemperar un poco las críticas krausistas al formalismo jurídico, puesto que hoy sabemos que afirmar la dimensión coactiva del Derecho no significa rebajar el Derecho al nivel de la simple fuerza física; al contrario, significa dignificar el necesario uso de la fuerza, de la coacción, haciéndola legítima, justa, cuando se ponen ella y el Derecho -como demandan los krausistas- al servicio de fines humanos como la libertad, la paz, la justicia, la igualdad y el bienestar de todos los hombres, y todo ello es lo que parece que quizá desde la filosofía jurídica krausista se subestima o no se tiene suficientemente en cuenta.

Otro factor a tener en cuenta es que este sector de la burguesía española, al orientar siempre su ideario en contra de la fuerza y hacia la suavización del Estado, hacia la desestatización, parece ignorar repetidamente que un sistema de fuerza, un Estado poderoso no nos aboca necesariamente a los intereses de una oligarquía sino que, si ese Estado cumple con ciertos requisitos constitucionales, también está en condiciones de garantizar el libre juego político de la democracia liberal. Si no se afirmara este Estado coactivo que cuida de principios y de las exigencias éticas de una comunidad, las propuestas de una teoría de la justicia, de ese "deber ser" jurídico y social formulado por la ética krausista, resultaría muchas veces reducida a un mero desiderátum ineficaz, inoperante, cuando no directamente, un vano intento. Toda moralidad pide pues, ser reconocida por un Derecho positivo, que es el que le da efectividad, y en la medida en que las propuestas de reforma krausistas se hacen desde un plano meramente eticista o educador, parten de una imposibilidad de base para hacerse efectivas y adolecen de un enfrentamiento real con la génesis de la conflictividad. Su desprecio por el formalismo, por la mecánica del legalismo, es, a su vez, un peligroso desprecio hacia la estructuración exterior de la seguridad jurídica y política que había ideado el liberalismo clásico (separación de poderes, control jurídico, etc.) y que tan importante ha sido para la civilización moderna.

Por lo tanto, podemos concluir que, a pesar de la coherencia liberal de la filosofía jurídica krausista en muchos aspectos de su doctrina, su teoría presenta sin embargo 
algunas limitaciones e insuficiencias típicas de la mentalidad del intelectual burgués español de su tiempo como las que se acaban de señalar, que conviene tener presentes para aquilatar mejor su papel en la filosofía jurídica de su momento.

\section{La educación en el derecho: ¿panacea o instrumento social con un eficaz papel preventivo?}

Como puede apreciarse, los dos grandes pilares en que se asienta la doctrina de los krausistas, la educación y el derecho, quedan interconexionados de modo fundamental en su obra, porque ambos comparten el mismo objetivo: la reforma de la sociedad, pero siempre a través del individuo. A esta tesis, se añadía la idea que constituye la base de toda construcción jurídica krausista: que la reforma del Derecho y del ordenamiento social se puede llevar a cabo siempre a través de la educación del individuo. De estas premisas se derivaba la preferencia krausista por las soluciones educativas. Así se aprecia cómo el movimiento para conseguir una España libre en el krausismo se concretaba en una acción dirigida a formar una España culta, y cómo la función del Estado Nacional se veía circunscrita a la de servir fundamentalmente de Estado Educador.

Este planteamiento ha sido objeto de otras muchas objeciones de conjunto y aún de detalle que se han hecho al krausismo. Y es que, a pesar de que sus proyectos pedagógicos significaron en gran medida una reforma educativa y social determinantes, sin embargo, estuvieron bastante condicionados y determinados por la clase social de sus hombres, cuya visión unilateral para comprender cuáles eran los problemas reales de su sociedad y cómo deberían solucionarse, no fueron a veces las más eficaces. En este sentido se ha reprochado a Giner y Posada, como a todo el krausismo español en general, una falta de atención a las soluciones estructurales y técnicas, de reforma de la industria y de la agricultura, y una excesivamente marcada preferencia por las vías lentas de la enseñanza y la moralidad que, aplicadas al contexto de la realidad española a la que estaban destinadas, iban a resultar desgraciadamente poco operativas:

Falta, desde luego, un planteamiento del problema desde plataformas más reales y operativas. Hay una, no sé si consciente o inconsciente, infravaloración de otros "atrasos" más inmediatos de la clase trabajadora: los que se derivan de su inserción como mano de obra en una determinada relación de producción que les constriñe a vivir en durísimas condiciones de subalimentación, de mísera vivienda, etc. Creer o pretender creer que la cultura iba a solucionar también estos problemas, que iba a llevar al ánimo de los patronos la "conciencia del deber" y que iba a corregir las desigualdades reales, creer esto, digo, forma parte de la utopía krausista, tan unilateral en algunos aspectos, tan determinada por el origen social de sus hombres ${ }^{24}$.

Como muy bien ha señalado el profesor Francisco Laporta, la creencia en que la cultura era suficiente para solucionar los problemas estructurales y técnicos por los que estaba atravesando España, revela, en efecto, el carácter burgués e inoperante del

24 Laporta, F.: Adolfo Posada: Política y Sociología en la crisis del Liberalismo español. Madrid, Editorial Cuadernos para el Diálogo, Edicusa, 1974, p. 86. 
empeño. Su meritoria petición, a través de la educación, de una serie de imperativos morales como los de la libertad e igualdad sustanciales entre los hombres, se veía pues lastrada por la indefensión de una ética, de un imperativo moral que no lograba imponerse como imperativo real respaldado por la fuerza del Estado, y que les impedía dar un paso adelante en el reconocimiento social de sus demandas éticas.

Así ha sido apuntado por el profesor Elías Díaz, quien ha sabido apreciar muy bien los aspectos problemáticos del eticismo krausista por su descuido de los citados aspectos infraestructurales y materiales que demandaban una toma de medidas con mayor prontitud y urgencia:

No ha dejado de ponerse de relieve que esa concepción eticista puede de hecho conducir a la consolidación, cuando no sin más aceptación, de un modelo de sociedad que tiende a minimizar el conflicto real y, por lo tanto, -se aducía desde sectores obreros y socialistasa ocultar la existencia de la lucha de clases, sustituyéndolo por un modelo basado en una relación esencialmente armónica de los diferentes grupos y fuerzas sociales. No se olvide que estamos hablando de la España de finales del XIX y, todo lo más, del primer tercio de nuestro siglo $\mathrm{XX}^{25}$.

Esto es muy característico de la situación del intelectual liberal en las primeras décadas del siglo xx, el negarse a mirar a su propia circunstancia histórica, el negarse a comprometerse con su realidad bajo el pretexto de que la técnica, las medidas coactivas, envilecen la vida del espíritu. Por ello, las medidas krausistas fueron consideradas en su época, ciertamente respetables y pertinentes, pero en muchos aspectos, insuficientes de cara a la acuciante problemática social y las necesidades apremiantes de la circunstancia histórica española en que se encontraban, las cuales reclamaban, por aquel entonces, otras medidas de primera necesidad para afrontar la problemática de la sociedad industrial.

\section{Consideraciones finales}

Dicho esto, y una vez indicadas las insuficiencias del liberalismo krausista para afrontar algunas de las problemáticas de su propio contexto histórico, conviene subrayar algunas de las virtudes del amplio y profundo programa krausista de reformas legislativas y educativas, en cuyo sentido nos gustaría abundar aquí.

Debe pues recordarse la actualidad que tienen muchas de las propuestas educativas krausistas, lo cual se hace patente en el marco de la evolución que los sistemas educativos han experimentado históricamente y que puede constatarse, por ejemplo, en que las recientes iniciativas educativas han asimilado la necesidad de incorporar la mayoría de los principios pedagógicos institucionistas. En particular, la educación en el sistema krausista asumió una importante responsabilidad social y sus proyectos educativos constituyeron un valioso acercamiento cultural de cierto sector de la clase burguesa española de finales del siglo XIX especialmente abierto a

25 Díaz, E.: "Krausismo e Institución Libre de Enseñanza: Pensamiento Social y Político”. En: Álvarez Lázaro, Pedro. F., (ed. lit.), Menéndez Ureña, Enrique (ed. lit.): La actualidad del krausismo en su contexto europeo. Madrid, Editorial Parteluz, Fundación Duques de Soria, Universidad Pontificia Comillas, Colección del Instituto de Investigación sobre Liberalismo, Krausismo y Masonería, 16, España, 1999, p. 240. 
la problemática social, lo cual puede verificarse en su reivindicación del derecho a la educación, como un derecho fundamental de todo hombre, que actúa en su sistema como uno de los instrumentos más eficaces de luchar contra la discriminación social y la mejor herramienta para garantizar la igualdad de oportunidades; también es reseñable el interesante papel preventivo que cumple la educación, sobre todo, la educación en el derecho, dentro de la teoría jurídica krauseana. Así lo expresa su discípulo, Adolfo Posada, refiriéndose al interés de Giner por esos dolores sociales y su gran compromiso con su contexto histórico y social: "el Sr. Giner ha consagrado los mejores años de su vida a fundar y conservar la Institución Libre de Enseñanza, y a mantener vivo, aumentándolo cada día, el interés doctrinal y práctico de la juventud por los problemas de la educación y por los problemas y dolores sociales"26.

En efecto, estas son sólo algunas de las numerosas virtudes de la filosofía krausista y, a pesar de sus limitaciones o insuficiencias, deben tenerse presentes, pues no sería lícito olvidar su énfasis en la educación como una herramienta eficaz, característica de su coherencia liberal, para emprender la lucha abierta que el krausismo protagonizó contra los totalitarismos de su época.

En resumen, puede afirmarse que, a pesar de las críticas hechas a la teoría krausista por no ser la solución más idónea o eficaz para su realidad social concreta, razón por la cual se ha acusado a su teoría de estar viciada del idealismo armonicista decimonónico, no puede decirse que su empeño fuera completamente inoperante por las razones que se han expresado en estas páginas. Conviene, a este propósito, reparar en que su reformismo social basado principalmente en medidas pedagógicas, fue un honesto intento práctico de considerable importancia para reconducir la solución del enfrentamiento a niveles de posibilidad, y que sentó las bases de lo que luego serían reconocidos como derechos o exigencias de justicia básicas de nuestra sociedad. Que su realidad social ignorara la realización efectiva del ideal krausista en cuestión no desmiente la excelencia de éste sino sólo su falta de éxito histórico-social por razones, que bien pueden considerarse circunstanciales y salvables.

En consecuencia, su falta de eficacia no desalienta nuestro empeño por buscar señales de excelencia y nobleza en la obra decimonónica de estos pensadores krausistas españoles. Al contrario, consideramos que sin esta crítica krausista del conformismo general ante un status quo que, en su momento, parecía insuperable, su presente se habría extendido indefinidamente y sin solución de continuidad hasta nuestros días. Sólo la crítica de pensadores como los krausistas ha sido capaz de ofrecer una posibilidad de ruptura, y de plantear posibilidades alternativas que siguen demandando nuestra atención, pues las cuestiones jurídicas y sociales que los krausistas se plantearon continúan siendo preguntas intemporales y universales tan revolucionarias hoy como en la época de Giner.

\section{Referencias bibliográficas}

Calderón Arana, A.: "El contrato y el Derecho". BILE. X, tomo II, 1886, pp. 252-254, 264267.

(Clarín) García-Alas y Ureña, L.: "El derecho y la moralidad". Revista Europea. t. XII, n. ${ }^{\circ}$ 240, 29 septiembre 1878, pp. 260-267, 292-297, 326-330, 360-364, 399-403, 427-443, $461-466,487-495,532-527$.

26 Posada, A.: "Los estudios sociológicos en España". BILE. XXIII, tomo II, 1899, p. 246. 
Díaz, E.: La filosofía social del krausismo español. Madrid, Editorial Cuadernos para el diálogo, 1973, 279 pp. (Última edición, Editorial Debate, Madrid, 1989).

Díaz, E.: "Krausismo e Institución Libre de Enseñanza: Pensamiento Social y Político". En: Álvarez Lázaro, P. F., (ed. lit.), Menéndez Ureña, E. (ed. lit.): La actualidad del krausismo en su contexto europeo. Madrid, Editorial Parteluz, Fundación Duques de Soria, Universidad Pontificia Comillas, Colección del Instituto de Investigación sobre Liberalismo, Krausismo y Masonería, 16, España, 1999.

Enériz Olaechea, F. J.: "El proyecto de Constitución Federal de la I República Española (1873)". En: Revista jurídica de Navarra. No 37, 2004.

Giner de los Ríos, F.: "Notas de Sociología”. BILE. XXII, tomo II, 1898, pp. 348-350.

Giner de los Ríos, F.: “Aspectos del anarquismo”. BILE. XXIII, tomo I, 1899, pp. 88-90.

Giner de los Ríos, F.: "Sobre el concepto de la ley en el Derecho positivo". BILE. LV, tomo I, 1931, pp. 218-224.

Giner de los Ríos, F. y Calderón Arana, A.: Prolegómenos del derecho. Principios de derecho natural, sumariamente expuestos por Francisco Giner, profesor de Filosofía del Derecho en la Universidad de Madrid, y Alfredo Calderón, alumno de la misma. Madrid, OO.CC., t. I, 1916.

Giner de los Ríos, F. y Calderón Arana, A.: Resumen de Filosofía del Derecho, por Francisco Giner, profesor en la Universidad de Madrid y en la „Institución libre de Enseñanza“, y Alfredo Calderón, doctor en Derecho. Madrid, OO.CC., Tomo I, t. XIII, 1926, 323 pp.

Giner de los Ríos, F. y Calderón Arana, A.: Resumen de Filosofía del Derecho, por Francisco Giner, profesor en la Universidad de Madrid y en la „Institución libre de Enseñanza “, y Alfredo Calderón, doctor en Derecho. Madrid, OO.CC., Tomo II, t. XIV, 1926, 284 pp.

Greppi, A.: La democracia y su contrario. Representación, Separación de Poderes y Opinión Pública. Madrid, Trotta, 2012, 216 pp.

Laporta, F.: Adolfo Posada: Política y Sociología en la crisis del Liberalismo español. Madrid, Editorial Cuadernos para el Diálogo, Edicusa, 1974.

Platón: La República. Introducción de Manuel Fernández-Galiano, Traducción de José Manuel Pabón y Manuel Fernández-Galiano, Madrid, Alianza Editorial, Clásicos de Grecia y Roma, 2006, p. 605.

Posada, A.: "Los estudios sociológicos en España". BILE, XXIII, tomo II, 1899, pp. 214-224, 246-286.

Posada, A.: "Prólogo". En: Giner de los Ríos, F.; Calderón, A.: Prolegómenos del derecho. Principios de derecho natural, sumariamente expuestos por Francisco Giner, profesor de Filosofía del Derecho en la Universidad de Madrid, y Alfredo Calderón, alumno de la misma. Madrid, OO.CC., t. I, 1916.

Posada, A.: "El fin del Estado". BILE. XXXIX, tomo I, 1915, pp. 138-145.

Posada, A.: "La soberanía”. BILE. XXXIX, tomo II, 1915, pp. 246-252.

Querol Fernández, F.: La filosofía del derecho de K.Ch.F. Krause. Con un apéndice sobre su proyecto europeísta. Universidad Comillas, Unión Editorial, Madrid, 2000, 492 pp.

Recaséns Siches, L.: Panorama del pensamiento jurídico en el siglo XX. México, Editorial Porrúa, primer tomo, primera edición, 1963.

Ríos Urruti, F. de los: "La obra de la cultura: Ética y Educación". BILE. XXXII, tomo II, 1908, pp. 303-305.

Ríos Urruti, F. de los: "La filosofía política en Platón”. Obras Completas. Madrid, Anthropos Editorial, Fundación Fernando de los Ríos, 1997, pp. 5-58.

Vázquez-Romero, J. M.: Francisco Giner de los Ríos. Actualidad de un pensador krausista. Madrid, Marcial Pons, Ediciones de Historia, 2009, 309 pp. 
Vázquez-Romero, J. M.: "Sociedad, Derecho y Ciencia en los escritos de Giner de los Ríos". En: Álvarez Lázaro, Pedro. F., Vázquez-Romero, José Manuel (Eds.): Krause, Giner y la Institución Libre de Enseñanza. Madrid, Editorial Parteluz, Universidad Pontificia Comillas, 2005, pp. 107-129.

Vázquez-Romero, J. M.: "La sociedad científica en los escritos ginerianos del sexenio". En: El Basilisco, (nº 38, enero-diciembre, 2006), pp. 77-94. 